\title{
Screening Particle Sizing
}

National Cancer Institute

\section{Source}

National Cancer Institute. Screening Particle Sizing. NCI Thesaurus. Code C113040.

Separation of dry particles into size-differentiated fractions by mechanical movement through fixed mesh screens. 